\title{
Hollow $Y$ zeolite single crystals: synthesis, characterization and activity in the hydroisomerization of $\boldsymbol{n}$-hexadecane
}

\author{
Céline Pagis ${ }^{1,2}$, Christophe Bouchy ${ }^{2}$, Mathias Dodin ${ }^{2}$, Raquel Martinez Franco $^{2}$, David Farrusseng ${ }^{1}$, and Alain Tuel ${ }^{1, *}$ \\ ${ }^{1}$ Université de Lyon, Université Claude Bernard Lyon 1, CNRS, IRCELYON - UMR 5256, 2 Avenue Albert Einstein, \\ 69626 Villeurbanne Cedex, France \\ ${ }^{2}$ IFP Energies nouvelles, Rond-point de l'échangeur de Solaize, BP 3, 69360 Solaize, France
}

Received: 28 June 2018 / Accepted: 12 March 2019

\begin{abstract}
Hollow Y zeolite single crystals have been obtained from a conventional NaY zeolite following a three-step process involving a severe dealumination of the zeolite with silicon tetrachloride (step \#1), followed by an acid washing under mild conditions ( step \#2) and finally a selective dissolution of the crystals core in the presence of protective $\mathrm{Al}$ species (step \#3). Crystals are characterized by the presence of a regular internal cavity with $0.1-0.2 \mathrm{~nm}$ thick microporous walls. They contain a relatively low framework Al content but significant amounts of extraframework Al oxide species mainly located on the external surface of the crystals. Hollow crystals have been mixed with a Pt-supported alumina binder and used as catalysts in the hydroisomerization of $n$-hexadecane. Compared to the corresponding bulk crystals obtained after step \#2, their higher activity has been attributed to a better efficiency, directly resulting from the presence of the cavity.
\end{abstract}

\section{Introduction}

Zeolites are microporous aluminosilicates whose framework is built up from corner sharing $\mathrm{TO}_{4}$ tetrahedra with $\mathrm{T}=\mathrm{Si}^{4+}$ or $\mathrm{Al}^{3+}$. The members of the zeolite family differ essentially by their composition and by the spatial arrangement of tetrahedra, which generates structures with interconnected channels and cavities of molecular dimension. Because of the presence of trivalent $\mathrm{Al}^{3+}$ at tetrahedral sites, the negative charge of the framework has to be compensated by extraframework cations located inside the pores. When those cations are protons, zeolites behave like solid acids and they find many applications in catalytic processes such as alkylation or hydrocracking [1-4]. Zeolite Y, the Si-rich member of the faujasite family, was discovered in 1964, and it has been one of the most important components of Fluid Cracking Catalyst (FCC) in oil industry for half a century $[2,5]$. Indeed, besides a low production cost, Y zeolite possesses unique characteristics, in particular a high thermal stability, a high porous volume as well as a significant Brønsted acidity. As for all other zeolites, reactions that take place in the micropores are generally limited by the diffusion of reactants and/or products, particularly when molecules are larger than the pore size, i.e., with a kinetic diameter higher than $0.75 \mathrm{~nm}[6]$. Low diffusivity increases the residence time of molecules in the porosity, which can dramatically influence the catalytic activity as

\footnotetext{
* Corresponding author: alain.tuel@ircelyon.univ-lyon1.fr
}

well as selectivities, for example by favoring over-cracking reactions in acid-catalysis. Molecular transport in zeolite frameworks can be improved by decreasing the mean diffusion length, for example by working with crystals as small as possible [7-10]. However, nanometric crystals are not always easy to synthesize and, in the particular case of $\mathrm{Y}$ zeolite, they are generally less stable than the corresponding micrometric counterparts $[9,11]$. Industrially, the stabilization of $\mathrm{Y}$ zeolites by moderate dealumination creates internal mesopores in which diffusion is several orders of magnitude faster than in micropores [12-14]. Desilication can also be used to create an additional array of mesopores in zeolite crystals, leading to the so-called hierarchical zeolites [15-18]. Hierarchical Y zeolites have shown remarkable catalytic conversions in the transformation of bulky molecules for which microporous analogs were almost inactive [19-21]. However, demetalation techniques need to be performed very carefully, otherwise they can cause some loss of crystallinity, modify the chemical composition of the zeolite framework and deposit amorphous matter in the micropores. Moreover, the development of mesopores does not only change the mean diffusion length, it also drastically increases the external surface, which can have a negative impact on the selectivity.

We have recently reported a new concept to reduce the diffusion length in Y zeolite crystals while keeping a micrometric size and a highly crystalline framework [22-26]. It consists in removing selectively the central part of zeolite crystals, generally by desilication of Si-rich regions under 
strong alkaline conditions. Besides reducing the average diffusion length, this "nanobox" architecture has proved to be particularly adapted for the encapsulation of metal nanoparticles, leading to nanoreactors with enhanced stability and selectivity [27-30]. In the particular case of zeolite $\mathrm{Y}$ with the faujasite structure, hollow single crystals have been obtained by a multi-step process involving successive dealumination and desilication steps [26]. In the absence of mesoporosity, this procedure preserves the external surface of the crystals but the diffusion length is reduced to the wall thickness, typically less than $150 \mathrm{~nm}$. In the present work, we report in detail the different steps of the transformation of bulk NaY crystals into their hollow counterparts, with a particular attention to key parameters that determine the success of the process. Moreover the acidity of hollow Y zeolite crystals is characterized by infrared spectroscopy of adsorbed pyridine and Pt-loaded crystals are used in the catalytic hydro-isomerization of $n$-hexadecane $\left(n-\mathrm{C}_{16}\right)$. Results are compared to those obtained on bulk crystals and the advantages of the hollow morphology on the activity are discussed.

\section{Experimental}

\subsection{Synthesis methods}

Hollow Y zeolite has been obtained by dealumination of standard NaY crystals with silicon tetrachloride, followed by washing in $\mathrm{HCl}$ solutions and finally selective desilication by $\mathrm{NaAlO}_{2}$ solutions at low temperature.

\subsubsection{Synthesis of the parent NaY zeolite}

$\mathrm{NaY}$ zeolite was prepared using a standard procedure from the crystallization of a gel with the following composition: $4 \mathrm{Na}_{2} \mathrm{O}: 1 \mathrm{Al}_{2} \mathrm{O}_{3}: 10 \mathrm{SiO}_{2}: 180 \mathrm{H}_{2} \mathrm{O}$ [31]. The gel was aged for $24 \mathrm{~h}$ at room temperature and then heated at $100{ }^{\circ} \mathrm{C}$ for another $24 \mathrm{~h}$ to promote crystallization. The crystalline powder was then filtered, washed with distilled water and dried at $100{ }^{\circ} \mathrm{C}$ overnight.

\subsubsection{Step \#1: dealumination procedure}

$2 \mathrm{~g}$ of the $\mathrm{NaY}$ zeolite were placed in a tubular quartz reactor and heated under nitrogen flow $(60 \mathrm{~mL} / \mathrm{min})$ at $350{ }^{\circ} \mathrm{C}$ (heating rate of $10^{\circ} \mathrm{C} / \mathrm{min}$ ). Temperature was maintained at $350{ }^{\circ} \mathrm{C}$ for $2 \mathrm{~h}$ to ensure a complete dehydration of the zeolite. After cooling temperature to $250{ }^{\circ} \mathrm{C}$, the nitrogen flow passing through the zeolite bed was saturated at room temperature with silicon tetrachloride. Temperature was then increased to $560^{\circ} \mathrm{C}\left(\right.$ rate $\left.=10^{\circ} \mathrm{C} / \mathrm{min}\right)$ and the zeolite was treated at this temperature for $1 \mathrm{~h}$. Then the reactor was purged for $1 \mathrm{~h}$ with pure nitrogen. After cooling to room temperature the sample was collected, washed with distilled water and dried overnight at $100{ }^{\circ} \mathrm{C}$.

\subsubsection{Step \#2: acid washing}

The dealuminated zeolite was then treated with $\mathrm{HCl}$ solution $(0.1 \mathrm{M})$. One gram of solid was dispersed in $20 \mathrm{~mL}$ of $\mathrm{HCl}$ solution, the mixture was heated at $80{ }^{\circ} \mathrm{C}$ and maintained at this temperature for $4 \mathrm{~h}$ under vigorous stirring. The solid was recovered by filtration, washed with distilled water and dried overnight at $100^{\circ} \mathrm{C}$. At this stage, the dealuminated, acid-washed zeolite is still purely microporous and it is further denoted "bulk zeolite" in the following.

\subsubsection{Step \#3: selective desilication}

After step \#2, the zeolite was dispersed in an aqueous solution of sodium aluminate (Riedel de Haën, $0.01 \mathrm{M}$ ) with a solid-to-liquid ratio of 1:60. After a short homogenization period, the solution was slowly heated and kept at $60{ }^{\circ} \mathrm{C}$ for $4 \mathrm{~h}$ under vigorous stirring. The suspension was then filtered, washed with distilled water and dried overnight at $100{ }^{\circ} \mathrm{C}$. As discussed later, desilication generates an internal cavity in the crystals, justifying the designation as "hollow zeolite" in the manuscript.

\subsection{Characterization techniques}

X-ray Powder Diffraction (XRD) patterns were recorded on a $\mathrm{D} 8$ advance diffractometer $(\mathrm{CuK} \alpha$ radiation, $\lambda=$ $1.5406 \AA$ ) equipped with a Ni filter and 1-D fast multi-strip detector (LynxEye, 192 channels on $2.95^{\circ}$ ). Measurements were performed at room temperature under air, between 4 and $80^{\circ}$ with $0.02^{\circ}$ steps and $0.5 \mathrm{~s}$ per step.

Scanning Electron Microscope (SEM) images were collected on a FEI ESEM-XL30 microscope under high vacuum (FEG source). Surface analysis by SEM is usually performed using low voltages $(<5 \mathrm{kV})$ on gold-coated solids. In the present case, bulk analysis was performed on uncoated crystals using a high voltage of $20 \mathrm{kV}$. Under such conditions, electrons penetrate deeply in the solid and give direct information about the presence of hollow structures by enhancing the contrast between regions of the crystal with different densities. A tiny amount of crushed sample was dispersed in ethanol and a drop of the suspension was deposited on standard holey carbon-covered copper Transmission Electron Microscopy (TEM) grids. TEM images were obtained on a JEOL $2010 \mathrm{LaB}_{6}$ microscope operating at $200 \mathrm{kV}$ using the same carbon-covered copper grids as those used in SEM measurements.

$\mathrm{N}_{2}$ adsorption/desorption isotherms were measured at $77 \mathrm{~K}$ on a Belsorp-mini (BEL-Japan) sorption apparatus. Circa $50 \mathrm{mg}$ of sample was outgassed under vacuum in a cell at $300{ }^{\circ} \mathrm{C}$ overnight prior to adsorption.

${ }^{29} \mathrm{Si}$ and ${ }^{27} \mathrm{Al}$ Magic Angle Spinning Nuclear Magnetic Resonance (MAS-NMR) spectra were obtained on a Bruker Avance III 500WB spectrometer equipped with a doublebearing probe head. Samples were spun at $10 \mathrm{kHz}$ in $4 \mathrm{~mm}$ zirconia rotors. Spectra were recorded with pulse lengths and recycle delays of $4 \mu \mathrm{s}(\pi / 3)$ and $100 \mathrm{~s}$ for ${ }^{29} \mathrm{Si}$, $1 \mu \mathrm{s}(\pi / 12)$ and $1 \mathrm{~s}$ for ${ }^{27} \mathrm{Al}$, respectively. Chemical shifts were referenced to Tetramethylsilane (TMS) and $\mathrm{Al}\left(\mathrm{H}_{2} \mathrm{O}\right)_{6}^{3+}$ for $\mathrm{Si}$ and $\mathrm{Al}$, respectively. Semi-quantitative Nuclear Magnetic Resonance (NMR) data were obtained using the same mass of zeolite and by collecting spectra with the same number of scans.

The acidity of the different zeolites was studied by adsorption/desorption of pyridine, followed by FourierTransformed Infrared (FTIR) spectroscopy. A zeolite wafer 
(approx. $20 \mathrm{mg}$ of zeolite, diameter $16 \mathrm{~mm}$ ) was placed in a FTIR quartz cell and outgassed at $450{ }^{\circ} \mathrm{C}$ for $10 \mathrm{~h}$ under vacuum. The temperature was then decreased to $150{ }^{\circ} \mathrm{C}$ and pyridine was adsorbed at that temperature for 10 min. Pyridine was then desorbed at increasing temperatures and the corresponding infrared spectra were collected at room temperature, using a Nexus 1 (ThermoOptek Nicolet) spectrometer. For each spectrum, 64 scans were accumulated with a resolution of $4 \mathrm{~cm}^{-1}$.

\subsection{Catalytic measurements}

The hydroisomerization of $n$ - $\mathrm{C}_{16}$ was performed at IFPEN on a high-throughput catalytic test unit. Typically, catalysts were obtained by mixing an acidic $\mathrm{HY}$ zeolite with a $\mathrm{Pt} / \mathrm{Al}_{2} \mathrm{O}_{3}$ binder. Platinum was introduced on alumina by impregnation with a solution of $\mathrm{H}_{2} \mathrm{PtCl}_{6} \cdot 6 \mathrm{H}_{2} \mathrm{O}$ in the presence of $\mathrm{HCl}$ as competitive adsorbate. The impregnated solid was dried overnight at $110{ }^{\circ} \mathrm{C}$ and then calcined in an air flow at 150,250 , and $350^{\circ} \mathrm{C}$ for $1 \mathrm{~h}$ each and finally at $520{ }^{\circ} \mathrm{C}$ for $2 \mathrm{~h}$ using a heating rate of $5{ }^{\circ} \mathrm{C} / \mathrm{min}$. The resulting $\mathrm{Pt}$ content was 0.26 wt.\% with a dispersion of $86 \%$. After mixing 90 wt. $\%$ of $\mathrm{Pt} / \mathrm{Al}_{2} \mathrm{O}_{3}$ with 10 wt.\% hollow or bulk HY (leading to an overall $\mathrm{Pt}$ content of 0.23 wt.\%), the powder was pelletized with a hydraulic press, crushed and sieved to obtain a pellet size between 200 and $300 \mu \mathrm{m} .320 \mathrm{mg}$ of those particles were introduced in an inox ${ }^{\circledR} 4 \mathrm{~mm}$ diameter tubular reactor along with zirblast ${ }^{\circledR}$ beast to complete the empty volume. The catalyst was pretreated by heating the filled reactor at $150{ }^{\circ} \mathrm{C}$ for $30 \mathrm{~min}$ under nitrogen flow $(10 \mathrm{~mL} / \mathrm{min})$, then hydrogen was introduced $(21 \mathrm{~mL} / \mathrm{min})$ and the temperature was increased to $450{ }^{\circ} \mathrm{C}$ at a heating rate of $5{ }^{\circ} \mathrm{C} / \mathrm{min}$. Catalytic tests were performed at $1.1 \mathrm{MPa}$ total pressure, a molar $\mathrm{H}_{2}$ to $n$ - $\mathrm{C}_{16}$ ratio of 10 , reaction temperatures between 180 and $350{ }^{\circ} \mathrm{C}$ and a weight hourly space velocity of $2 \mathrm{~g} n$-hexadecane per gram of catalyst per hour.

\section{Results and discussion}

\subsection{Synthesis of hollow $Y$ zeolite crystals}

The formation of hollow Y zeolite crystals is a complex process in which each step is strongly impacted by the amount, the nature and the distribution of $\mathrm{Al}$ species in the zeolite crystal. Originally, $\mathrm{NaY}$ crystals possess a high $\mathrm{Al}$ content and it is commonly accepted that $\mathrm{Al}$ species are homogeneously distributed throughout the crystals [32]. Under such conditions, desilication by sodium hydroxide solutions is not selective and it affects all parts of the crystals, creating a random array of extended mesopores. This "unselective" desilication, which has been widely used to create the so-called "hierarchical zeolites", greatly contributed to improve their catalytic activity, particularly in the case of large molecules that diffuse slowly in micropores [15-21]. Selective dissolution of crystal cores necessitates crystals with a heterogeneous composition and it can be achieved only after the original $\mathrm{Al}$ distribution has been modified. It has been widely reported that the desilication rate of an aluminosilicate framework depends on the $\mathrm{Al}$ content and that it is maximum for $\mathrm{Si}: \mathrm{Al}$ atomic ratios between 20 and 50 [33]. The parent NaY zeolite was thus dealuminated by silicon tetrachloride to reach an appropriate framework $\mathrm{Al}$ content (step \#1 of the process). During the treatment, the global $\mathrm{Si} / \mathrm{Al}$ ratio of the solid increased from 2.45 to 18.4 , clearly supporting a substantial dealumination of the solid. Framework dealumination was further confirmed by changes in the X-ray diffraction pattern. The crystallinity of the zeolite remained intact but reflections were shifted towards high angle values, indicating a decrease of the unit cell parameter $\mathrm{a}_{0}$ (Fig. 1). Many authors have already reported that the unit cell parameter of $\mathrm{Y}$ zeolites varied almost linearly with the framework $\mathrm{Al}$ content and this property has been often used to follow the degree of dealumination of a wide range of compositions, typically for zeolites with $\mathrm{Si} / \mathrm{Al}$ ratios between 2.7 and 37, i.e., containing 5-52 $\mathrm{Al}$ atoms per unit cell $[34,35]$. Following this relationship from FichtnerSchmittler, the unit cell parameter of the dealuminated zeolite corresponds to a $\mathrm{Si} / \mathrm{Al}$ atomic ratio of $29 \pm 3$, quite different from the value obtained by chemical analysis. The difference results from the presence of extraframework $\mathrm{Al}$ species in the zeolite, formed during dealumination with silicon tetrachloride. Extraframework $\mathrm{Al}$ species were evidenced by intense signals at $c a .30$ and $0 \mathrm{ppm}$ in the NMR spectrum of the dealuminated zeolite (Fig. 2) [32]. Those signals, which were not observed on the spectrum of the original $\mathrm{NaY}$ zeolite, are formally assigned to fiveand six-coordinate species present in aluminum oxides or hydroxides deposited in the porosity.

Faujasite crystals dealuminated by $\mathrm{SiCl}_{4}$ are generally heterogeneous with an aluminum distribution that depends on the extent of dealumination as well as the washing procedure $[36,37]$. For example, zeolites treated at temperatures above $360{ }^{\circ} \mathrm{C}$ and washed with water often show an

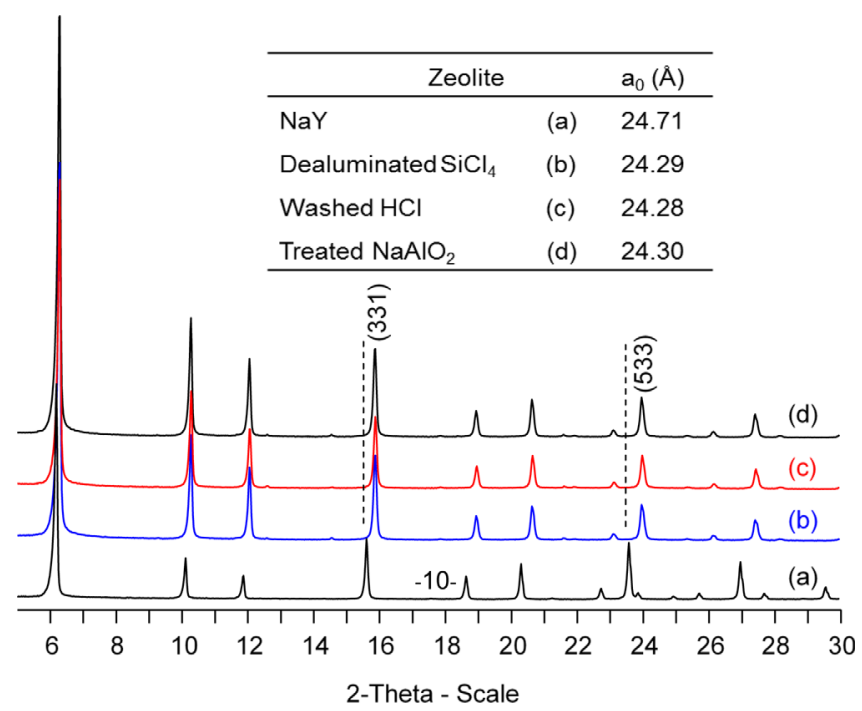

Fig. 1. XRD patterns of $\mathrm{Y}$ zeolite at the different steps of the process and corresponding unit cell axis values. (a) Parent $\mathrm{NaY}$ zeolite, (b) dealuminated with $\mathrm{SiCl}_{4}$, (c) dealuminated and washed with $\mathrm{HCl}$ and (d) finally desilicated with $\mathrm{NaAlO}_{2}$. Dashed lines help for the visualization of the shift of reflections (331) and (533). 

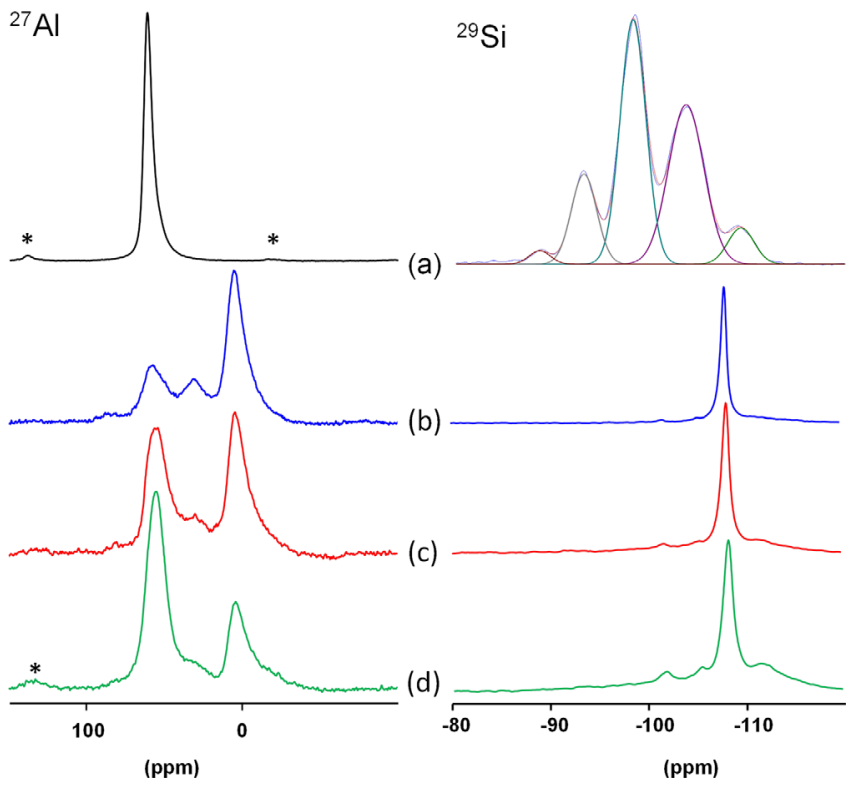

Fig. 2. ${ }^{27} \mathrm{Al}$ (left) and ${ }^{29} \mathrm{Si}$ (right) MAS NMR spectra of (a) the parent $\mathrm{NaY}$ zeolite, (b) after dealumination with $\mathrm{SiCl}_{4}$, (c) $\mathrm{HCl}$ washing and (d) finally desilication with $\mathrm{NaAlO}_{2}$. The ${ }^{29} \mathrm{Si} \mathrm{NMR}$ spectrum of $\mathrm{NaY}$ shows the deconvolution into five peaks corresponding to $\mathrm{Si}(n \mathrm{Si}, 4-n \mathrm{Al})$ environments that was used to calculate the framework $\mathrm{Si} / \mathrm{Al}$ ratio. Asterisks in ${ }^{27} \mathrm{Al} \mathrm{NMR}$ spectra indicate spinning side bands.

$\mathrm{Al}$ enrichment of the surface, favorable for the formation of hollow structures. In the present case, X-ray Photoelectron Spectroscopy (XPS) and SEM-EDX analysis both confirmed an excess of aluminum on the surface but none of the technique could discriminate between framework and extraframework species (Tab. 1) [26].

Nonetheless, the impossibility to form hollow structures upon treatment in $\mathrm{NaOH}$ solutions rather suggests that the excess of $\mathrm{Al}$ on the surface mainly results from extraframework species.

The presence of extraframework species partially blocks the porosity and reduces the accessible porous volume of the zeolite by ca. $20 \%$. Some of these species can be removed by washing the zeolite with diluted acid solutions (step \#2 of the process). After washing with a $0.1 \mathrm{M} \mathrm{HCl}$ solution, the overall $\mathrm{Si} / \mathrm{Al}$ ratio of the solid increases from 18.4 to 37.7, thus demonstrating the efficiency of the method to extract $\mathrm{Al}$ from the zeolite. Al removal is also supported by a significant decrease of the intensity of ${ }^{27} \mathrm{Al}$ signals at 30 and $0 \mathrm{ppm}$ in the NMR spectrum (Fig. 2). The persistence of the signal at $55 \mathrm{ppm}$ and the absence of additional shift of XRD reflections confirm that the acid primarily extracted extraframework species. Moreover, the drastic increase of the $\mathrm{Si} / \mathrm{Al}$ ratio measured by XPS indicates that extracted $\mathrm{Al}$ species were essentially removed from the surface of the crystals (Tab. 1).

Acid-washed, dealuminated $\mathrm{Y}$ zeolite crystals possess an aluminum content suitable for desilication with $\mathrm{NaOH}$ but the $\mathrm{Al}$ zoning is not sufficiently marked to form regular hollow structures. Consequently, the zeolite was desilicated with a solution of $\mathrm{NaAlO}_{2}$, which provided the required
Table 1. Atomic $\mathrm{Si} / \mathrm{Al}$ ratios of the zeolite after the different steps of the synthesis process.

\begin{tabular}{lccr}
\hline Zeolite & \multicolumn{3}{c}{$\mathrm{Si} / \mathrm{Al}$} \\
\cline { 2 - 4 } & $\begin{array}{c}\text { Chemical } \\
\text { analysis }\end{array}$ & $\mathrm{XRD}^{\mathrm{a}}$ & $\mathrm{XPS}$ \\
\hline Parent $\mathrm{NaY}$ & 2.5 & 2.6 & 2.4 \\
Dealuminated $\mathrm{SiCl}_{4}$ & 18.4 & 29 & 14.5 \\
Washed $\mathrm{HCl}$ & 37.7 & 33 & 46.5 \\
Desilicated $\mathrm{NaAlO}_{2}$ & 27.7 & 25 & 6.2 \\
\hline
\end{tabular}

${ }^{a}$ Estimated using the Fichtner-Schmittler equation [35].

alkalinity along with additional $\mathrm{Al}$ species (step \#3 of the process). At high $\mathrm{pH}$ values, some of the $\mathrm{Si}-\mathrm{O}-\mathrm{Si}$ bonds of the zeolite framework are broken, leaving defects which are particular positions for the reincorporation of $\mathrm{Al}$ species. Realumination is generally limited to the outer surface and transforms homogeneous crystals into heterogeneous crystals with an artificial $\mathrm{Al}$ zoning [38]. Reincorporation of $\mathrm{Al}$ species in the outer parts of the crystals was confirmed by XPS, a technique that probes the crystal structure within a thin layer beneath the surface (Tab. 1). In contrast to acid-washed bulk crystals for which the surface was deficient in aluminum, hollow crystals showed an enrichment in $\mathrm{Al}$ with a $\mathrm{Si} / \mathrm{Al}$ surface ratio of 6.2 , critically lower than the value obtained by chemical analysis of the whole crystal $(\mathrm{Si} / \mathrm{Al}=28)$. As for ZSM-5, this particular distribution of $\mathrm{Al}$ species protects the framework against desilication, and only the inner Si-rich parts of the crystals are dissolved. SEM and TEM pictures of the corresponding crystals show that the overall morphology has been preserved but that the interior has been dissolved, leaving a central cavity of about $0.8 \pm 0.1 \mu \mathrm{m}$ diameter (Fig. 3).

The crystallinity of the shell remains intact, as evidenced by the well-defined lattice fringes observed on sliced crystals. Additionally, a mesoporous corona is observed on the surface of the cavity, resulting from the partial dissolution of the zeolite framework. Compared to the acid-washed zeolite, both the microporous volume and Brunauer, Emmett and Teller (BET) surface area slightly increase (Tab. 2), likely because of a subsequent extraction of some extraframework $\mathrm{Al}$ species, as evidenced by ${ }^{27} \mathrm{Al}$ MAS NMR (Fig. 2). In contrast, the mesoporous surface increases by more than $90 \mathrm{~m}^{2} / \mathrm{g}$ as a result of the formation of the internal mesoporous corona (Tab. 2). The presence of a $\mathrm{H}_{2}$ hysteresis loop in the $\mathrm{N}_{2}$ adsorption/desorption isotherm of hollow crystals with a closure point at $p / p_{0}=0.47$ also supports the presence of an internal cavity and mesopores connected to the exterior by apertures smaller than $4 \mathrm{~nm}$.

\subsection{Key parameters and critical points of the synthesis}

As already mentioned the formation of regular hollow structures in faujasite crystals is not straightforward and many parameters have to be optimized at each step of the process. The first one concerns the degree of dealumination of the zeolite. If the $\mathrm{NaY}$ zeolite is treated at lower temperature 

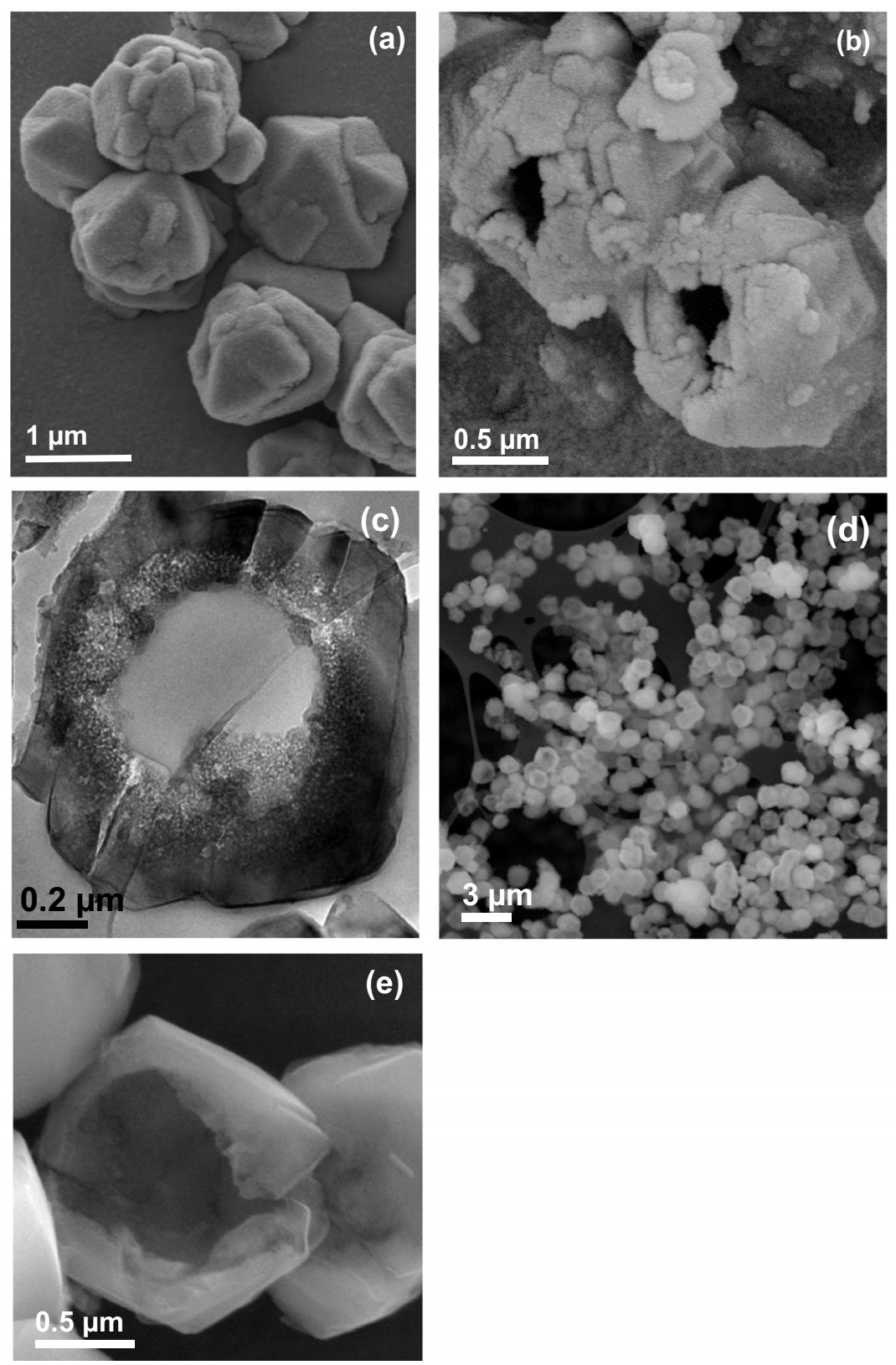

Fig. 3. SEM pictures (after metallization) of (a) the parent NaY zeolite and (b) the corresponding hollow crystals. (c) TEM picture of a sliced hollow crystal (70 nm thick) showing the mesoporous corona and (d, e) SEM pictures of hollow crystals using a high voltage of $20 \mathrm{kV}$ (Sect. 2.2 for experimental details).

or for a shorter time, it is less dealuminated and hollow structures are not formed after the whole process. In a recent publication, Yuan et al. succeeded in the preparation of hollow Y zeolite crystals from moderately dealuminated crystals (framework $\mathrm{Si} / \mathrm{Al}=6.4$ from XRD) [37]. The whole process is quite similar to that reported in the present work but it differs mainly by the acid concentration in step \#2 and the desilicating agent in step $\# 3$. According to the authors, dealuminated crystals possess a Si-rich surface resulting from the limited diffusion of $\mathrm{SiCl}_{4}$ in the zeolite micropores. After washing with a more concentrated $\mathrm{HCl}$ solution (0.5 M vs. $0.1 \mathrm{M})$, the Al-rich core is strongly dealuminated, leading to the formation of many internal framework defects. Defective cores are then preferentially eliminated by $\mathrm{NaOH}$ solutions in the absence of additional Al species. Nonetheless, the alkaline treatment has a strong impact on the crystallinity of the zeolite as evidenced by a significant decrease of intensities and the presence of a broad background characteristic of amorphous phase in the XRD pattern. Moreover, both the relatively high $\mathrm{Al}$ content of the zeolite and the use of sodium hydroxide as desilicating agent favor the formation of mesopores throughout the zeolite shell, which is not the case when Y zeolite crystals are more dealuminated. 
Table 2. Textural parameters of the zeolite after each step of the synthesis process.

\begin{tabular}{lccc}
\hline Zeolite & $S_{\text {BET }}\left(\mathrm{m}^{2} / \mathrm{g}\right)^{\mathrm{a}}$ & $S_{\text {Meso }}\left(\mathrm{m}^{2} / \mathrm{g}\right)^{\mathrm{b}}$ & $V_{\text {Micro }}\left(\mathrm{cm}^{3} / \mathrm{g}\right)^{\mathrm{c}}$ \\
\hline Parent NaY & 865 & 6 & 0.31 \\
Dealuminated $\mathrm{SiCl}_{4}$ & 669 & 18 & 0.23 \\
Washed $\mathrm{HCl}$ & 687 & 21 & 0.23 \\
Desilicated $\mathrm{NaAlO}_{2}$ & 709 & 111 & 0.24 \\
\hline
\end{tabular}

${ }^{a}$ BET method (constant $C$ positive and $p / p_{0}<0.1$ ).

${ }^{\mathrm{b}} t$-plot method (linear part between $0.34 \leq x$-axis $(\mathrm{nm}) \leq 1$ ).

${ }^{c}$ Volume of $\mathrm{N}_{2}$ adsorbed when the slope of adsorption branch becomes lower than $10^{3} \mathrm{~cm}^{3} \mathrm{~g}^{-1}$.

A second key point of the synthesis refers to the use of $\mathrm{NaAlO}_{2}$ as desilicating agent. Attempts to desilicate crystals with $\mathrm{NaOH}$ solutions were not successful, underlying the pivotal role of additional $\mathrm{Al}$ species in the formation of hollow structures. As already mentioned, the overall $\mathrm{Si} / \mathrm{Al}$ ratio of the zeolite decreases from 38 to 28 after the treatment, indicating that some $\mathrm{Al}$ species have been reincorporated in the zeolite. Nevertheless, aluminum reincorporation is not homogeneous and it affects essentially the surface of the crystals, as evidenced by the value of the $\mathrm{Si} / \mathrm{Al}$ ratio measured by XPS, which dramatically decreases from 46.5 to 6.2 (Tab. 1). Information on the real nature and location of these additional $\mathrm{Al}$ species are difficult to obtain because they concern a very thin layer on the outer surface of the crystals. In the absence of detectable shift of $\mathrm{XRD}$ reflections after treatment, it is difficult to conclude on the framework or extra-framework nature of these $\mathrm{Al}$ species. Minor changes can be observed in the ${ }^{29} \mathrm{Si} \mathrm{MAS}$ NMR spectrum but they are rather attributable to structural defects, formed during desilication of crystal cores and certainly located in the mesoporous corona. The main changes appear in ${ }^{27} \mathrm{Al}$ MAS NMR spectra, in particular in the intensity of the line at $55 \mathrm{ppm}$, generally assigned to four-cordinated $\mathrm{Al}$ atoms in zeolite framework. Indeed, the intensity of this line significantly increases while that of the signal around $0 \mathrm{ppm}$ decreases (Fig. 2). The decrease of the signal at $0 \mathrm{ppm}$ suggests that the alkaline treatment dissolves some of the extraframework $\mathrm{Al}$ oxide species and partially releases the porosity. This is confirmed by a slight increase of the BET surface area and pore volume as compared to the non-treated solid (Tab. 2). The relative increase of the signal at $55 \mathrm{ppm}$ could indicate that some of the $\mathrm{Al}$ species from $\mathrm{NaAlO}_{2}$ have been reincorporated in the zeolite framework. However, it has been reported that $\left(\mathrm{NaAlO}_{2}\right)_{x}\left(\mathrm{SiO}_{2}\right)_{1-x}$ ( $x$ can vary from $c a .0 .1$ to 1$)$ phases could be formed during desilication of zeolite frameworks in the presence of sodium ions [37, 39]. These amorphous phases are generally prepared by a sol-gel method and they have been characterized, in particular by solid state NMR. For $x<1$, the $\mathrm{Al}$ environment is exclusively fourcoordinated with a ${ }^{27} \mathrm{Al}$ chemical shift of $55 \mathrm{ppm}$ [40]. The chemical shift is similar to that of $\mathrm{Al}$ atoms in the zeolite framework and species cannot be distinguished on the basis of NMR chemical shift only. As for aluminosilicate gels, the position of the ${ }^{29} \mathrm{Si}$ MAS NMR signal changes with the composition, typically from $-80 \mathrm{ppm}$ for $x=1$ to $-105 \mathrm{ppm}$ for $x=0.1$. The line is generally broad and not easily observable when the amorphous phase is present at trace levels in a Si-rich zeolite, whose NMR signal is very intense. In order to discriminate between $\mathrm{Al}$ atoms of the zeolite framework and those of $\left(\mathrm{NaAlO}_{2}\right)_{x}\left(\mathrm{SiO}_{2}\right)_{1-x}$ phases, the concentration of the desilicating solution was doubled in view to increase the amount of amorphous phase in the hollow crystals. The increase of the $\mathrm{pH}$ value from 12 to 12.6 had no effect on the final morphology and regular cavities were obtained with size and shape very similar to those previously obtained with a more diluted solution. Nonetheless, the reduction of the microporous volume of the zeolite by $c a .32 \%$ from 0.24 to $0.17 \mathrm{~cm}^{3} / \mathrm{g}$, associated with the decrease of low-angle XRD reflection intensities suggested that a significant proportion of micropores were no longer accessible to $\mathrm{N}_{2}$ molecules and probably blocked by aluminosilicate amorphous species. High-Resolution TEM images of the zeolite clearly show the presence of a 5-6 nm thick amorphous layer which partially covers the surface of the crystals (Fig. 4).

Associated with an increase of the ${ }^{27} \mathrm{Al}$ MAS NMR signal at $55 \mathrm{ppm}$, the presence of this layer strongly supports an extraframework nature for the newly observed Al species. If such a layer is necessary to protect the surface from desilication, it could have a detrimental effect on catalysis by blocking partially the porosity of the zeolite. The alkalinity, temperature and duration of the desilication step are therefore of prime importance and they have to be perfectly controlled to obtain hollow crystals with high crystallinity and micropore volume.

\subsection{Structural characterization and acidity of bulk and hollow HY zeolites}

Pyridine thermodesorption followed by FTIR was used to estimate the amount of Brønsted and Lewis acid sites in bulk (crystals after the step \#2) and hollow (crystals after the step \#3) zeolites, previously exchanged in order to obtain their protonic forms. Values are taken after evacuating the zeolite wafer at $150{ }^{\circ} \mathrm{C}$ under vacuum for $2 \mathrm{~h}$ by measuring the intensity of the corresponding bands at $1545 \mathrm{~cm}^{-1}$ (Brønsted) and $1450 \mathrm{~cm}^{-1}$ (Lewis). The concentration of Brønsted and Lewis acid sites in the zeolites were estimated using integrated molar extinction coefficients of the literature [41]. For both zeolites, the concentration of Brønsted acid sites per gram of solid is relatively low, in agreement with the low $\mathrm{Al}$ content of the framework (Tab. 3). The Lewis-to-Brønsted $(L / B)$ ratio is 1.67 and 

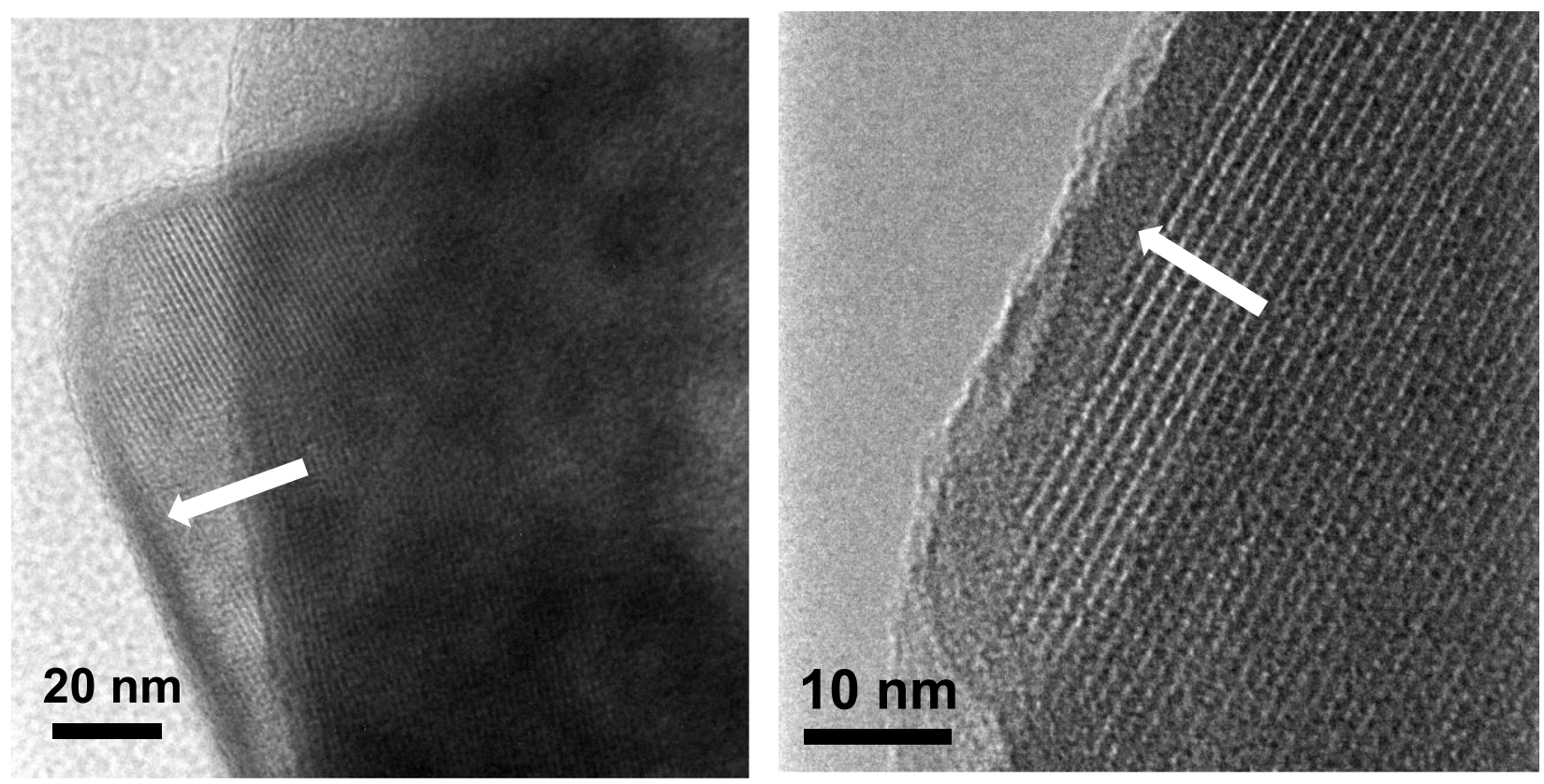

Fig. 4. TEM pictures of hollow Y zeolite crystals obtained by desilicating the zeolite with a $0.02 \mathrm{M} \mathrm{NaAlO}_{2}$ solution at $60{ }^{\circ} \mathrm{C}$ for $4 \mathrm{~h}$ (step \#3). Arrows indicate the amorphous aluminosilicate layer that covers the surface of some of the crystals.

Table 3. Density of Brønsted $(B)$ and Lewis $(L)$ acid sites in the different zeolites.

\begin{tabular}{lccc}
\hline Zeolite & $L(\mu \mathrm{mol} / \mathrm{g})$ & $B(\mu \mathrm{mol} / \mathrm{g})$ & $L / B$ \\
\hline Bulk HY & $50 \pm 15$ & $37 \pm 5.6$ & 1.35 \\
Hollow HY & $40 \pm 12$ & $24 \pm 3.6$ & 1.66 \\
CBV 720 & $109 \pm 33$ & $226 \pm 34$ & 0.48 \\
\hline
\end{tabular}

1.35 for hollow and bulk zeolites respectively, a value clearly higher than those obtained on commercial HY zeolites such as CBV-720 from Zeolyst ${ }^{\circledR}$ activated at the same temperature $(L / B=0.48)$. This can be explained by the large amount of extraframework $\mathrm{Al}$ species present in the protonic bulk and hollow zeolites, as evidenced by ${ }^{27} \mathrm{Al}$ MAS NMR. Indeed, the intensity of signals at 30 and 0 ppm even increased from the $\mathrm{Na}$ to the $\mathrm{H}$-form, indicating further framework dealumination upon exchange and calcination (Fig. 2). It has been widely reported that the number of sites titrated by large probe molecules such as pyridine could be considerably underestimated compared to the real number of acid sites in zeolite frameworks.

Based on a multi-technique approach, Boréave et al. estimated that the fraction of $\mathrm{Al}$ atoms interacting with pyridine in a series of commercial $\mathrm{HY}$ zeolites varied between 30 and $60 \%$, depending on the $\mathrm{Si} / \mathrm{Al}$ ratio and dealumination extent [42]. In the particular case of CBV-720, this fraction was $56 \%$, in excellent agreement with our data $(54 \%)$. This percentage was even lower when only Lewis acid sites were considered. Therefore, the very low population of acid sites observed in hollow and bulk HY zeolites suggests that the framework $\mathrm{Si} / \mathrm{Al}$ value is significantly higher than the value estimated by XRD on the corresponding $\mathrm{Na}$ zeolites, thus supporting additional dealumination upon exchange.

\subsection{Catalytic tests: hydroisomerization of $n$-hexadecane}

The hydroisomerization of long chain $n$-paraffins is generally performed on a bifunctional catalyst consisting of noble metal nanoparticles and an acidic zeolite mixed with alumina as binder $[43,44]$. The reaction scheme involves dehydrogenation of the alkane on metallic sites, followed by isomerization (or cracking) on acid sites and finally hydrogenation of the formed alkene on metal nanoparticles [45]. Accordingly, molecules have to diffuse from acidic to metallic sites, which makes that catalyst properties not only depend on the balance between (de)hydrogenation and acid functions but also on the distance between the two types of sites (intimacy criterion) [46-49]. For linear alkanes, it was recently reported that the conversion was independent on whether Pt nanoparticles were dispersed on the zeolite (mesoporous zeolite $\mathrm{Y}$ ) or on the binder ( $\gamma$-alumina), thus questioning the simple "the closer the better" interpretation of the intimacy criterion for positioning metal and acid sites [49]. However, the proximity between metallic and acid centers greatly influences the selectivity, cracking reactions being favored when $\mathrm{Pt}$ is dispersed on the zeolite, i.e., when acid and metal sites are close to each other. The influence of the crystal morphology on the activity in the hydroisomerization of $n-\mathrm{C}_{16}$ was studied on two catalysts that contain Pt nanoparticles dispersed on the alumina binder and differ by the morphology of the zeolite (bulk or hollow). First it was checked experimentally that the amount of platinum was sufficient to properly balance the acidic function. 
Since the rate of (de)hydrogenation on metal sites is fast compared to the rate of isomerization or cracking, the activity of a well-balanced catalyst is governed by the acidity and the structure of the zeolitic component [50]. In particular, the conversion directly depends on the amount, strength and accessibility of Brønsted acid sites in the zeolite framework.

Using a fixed bed reactor and considering global reaction order of 1 , the average Turnover Frequency (TOF) of the Brønsted acid sites $\left(\mathrm{mol}_{n-\mathrm{C} 16} / \mathrm{mol}_{\mathrm{Br} ø \mathrm{n}} / \mathrm{s}\right)$ along the reactor was calculated according to [51]:

$$
\mathrm{TOF}=\frac{r_{A}}{N_{S}}=\frac{F_{A}^{0}}{N_{S} W_{\text {cat }}} \ln \left(\frac{1}{1-X}\right)
$$

where $r_{A}$ is the reaction rate of $n$ - $\mathrm{C}_{16}$ hydroisomerization $(\mathrm{mol} / \mathrm{g} / \mathrm{s}), N_{S}$ is the number of acid sites per catalyst mass $(\mathrm{mol} / \mathrm{g}), F_{A}^{0}$ is the inlet molecular flow $(\mathrm{mol} / \mathrm{s}), W$ is the catalyst mass (g) and $X$ is the $n$-hexadecane conversion fraction. Due to their relatively low density of Brønsted acid sites, the two catalysts show moderate activities compared to a commercial CBV-720 HY zeolite. Moreover, the average Brønsted acid site TOF is higher for hollow crystals compared to their bulk analogue at a given reaction temperature (Fig. 5). During the hydroisomerization of $n$-decane over ZSM-5 zeolites, it was reported that the activity was not very sensitive to the crystal dimensions.

In particular, for similar $\mathrm{Al}$ contents, $8 \mathrm{~nm}$ thick ZSM-5 nanosheets were not more active than bulk zeolite crystals [52]. Therefore, it seems unlikely that the different activities observed between hollow and bulk faujasite crystals result solely from different zeolite morphologies. Considering hollow crystals as spheres of about $1.2 \mu \mathrm{m}$ outer diameter with $0.12 \mu \mathrm{m}$ thick regular walls, we can estimate that the mass of a hollow crystal is approx. $45 \%$ that of the corresponding bulk crystal. Consequently, the number of hollow zeolite crystals in the catalyst bed is $1 / 0.45=2.2$ times that of bulk crystals. This represents the same mass of usable zeolite assuming that crystals are fully utilized in the reaction. However, $n$-hexadecane being a long molecule, the reaction is certainly limited by diffusion and it is reasonable to assume that only a fraction of the zeolite crystal effectively participates in the reaction. We have recently reported that the hydrogenation of cyclohexene on similar bulk crystals was limited to an external layer of about $0.15 \mu \mathrm{m}$ depth, corresponding approx. to the wall thickness of hollow crystals [53]. If it is also the case for $n$-hexadecane, the activity of the catalyst containing hollow crystals is expected to be approx. twice that of bulk crystals with the same density of acid sites. As it can be observed in Figure 5, when the activity of bulk crystals is arbitrarily multiplied by a factor of $1 / 0.45=2.2$, the influence of the morphology is significantly reduced. Experimentally, the ratio of activities between catalysts containing hollow and bulk crystals varies with the conversion from $c a .1 .6$ at low conversion to 2.7 at $40-60 \%$ conversion. Values below 2 , which correspond to reaction temperatures below $230{ }^{\circ} \mathrm{C}$ are not very accurate because they are calculated for very low conversions $(<2 \%)$. On the contrary, a value of 2.7 suggests not

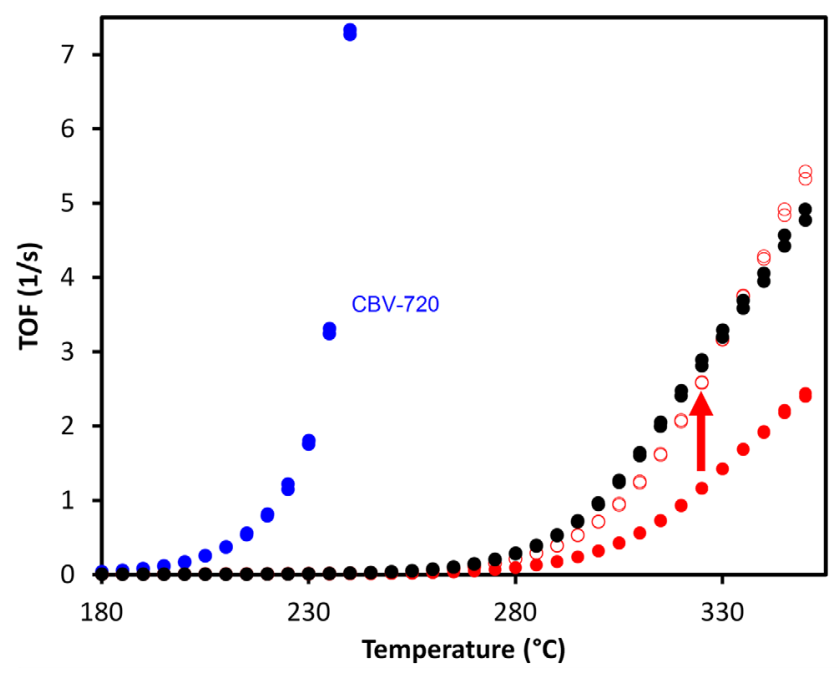

Fig. 5. Activity of the different catalysts with temperature. Bulk crystals (๑), hollow crystals $(\bullet)$ and a reference CBV-720 zeolite $(\bullet)$. Open symbols correspond to the activity of 2.2 times the amount of bulk crystals (see text for details).

only that bulk crystals are partially utilized in the reaction but also that hollow crystals are much more active, all other things being equal. Hollow and bulk crystals possess the same zeolite structure and quite similar compositions, characterized by relatively high $\mathrm{Si} / \mathrm{Al}$ ratios (Tab. 1). Apart from the composition, there are several factors that could explain the apparent higher Brønsted sites average turnover frequency of hollow crystals in the reaction. First, the acidity is very low and the determination of the density of Brønsted acid sites from the IR signal of adsorbed pyridine is only approximate. Moreover, the acidity is estimated after desorption at $150{ }^{\circ} \mathrm{C}$, which is quite low compared to the reaction temperature. An incorrect estimation of the amount of Brønsted acid sites obviously bias the calculation of the Brønsted sites average turnover frequency. Second, XPS spectroscopy has revealed that $\mathrm{Al}$ atoms were not homogeneously distributed in hollow crystals but preferentially located on the outer surface (Tab. 1).

At low conversions, both catalysts essentially form skeletal isomers, succeeded by cracking of carbon chains at conversions higher than 50\% (Fig. 6). For a similar conversion, the cracking selectivity is slightly lower on bulk crystals. No clear explanation for such phenomenon could be provided at the moment. Arguably the higher surface density of $\mathrm{Al}$ at the outer surface of the hollow crystal could favor successive reaction, i.e., cracking reaction.

For a given zeolite structure, the apparent activation energy of the reaction, which is $151 \pm 1 \mathrm{~kJ} / \mathrm{mol}$ for both catalysts, is independent of the zeolite crystal architecture (bulk or hollow) (Fig. 7).

This is confirmed by the value of $146 \pm 1 \mathrm{~kJ} / \mathrm{mol}$ obtained on the commercial CBV-720 zeolite, which possesses a higher $\mathrm{Al}$ content as well as a very different morphology. For bulk crystals, this activation energy is 


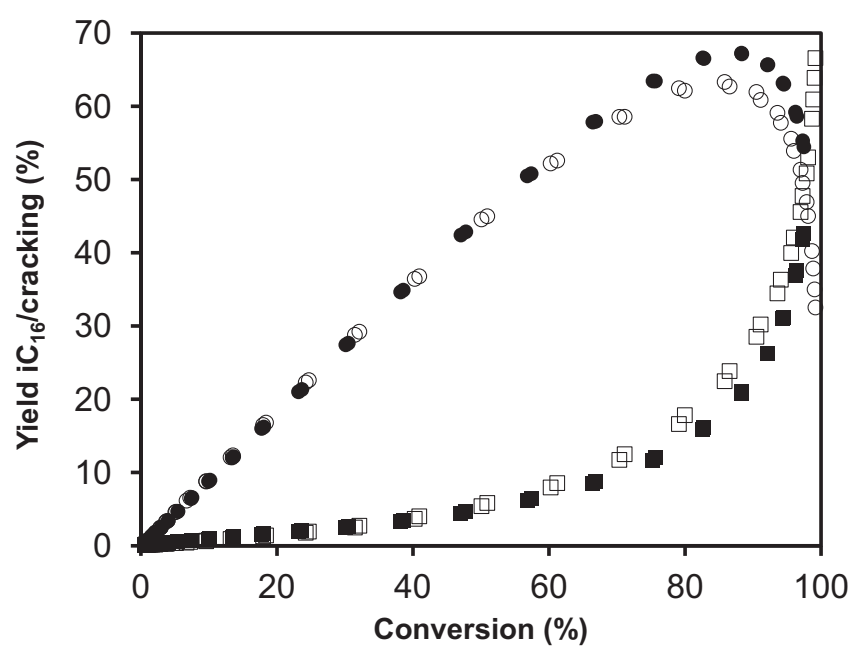

Fig. 6. Yields in $n$-C16 isomers (disks) and cracking products (squares) with reaction temperature for bulk (filled symbols) and hollow (open symbols) zeolites.
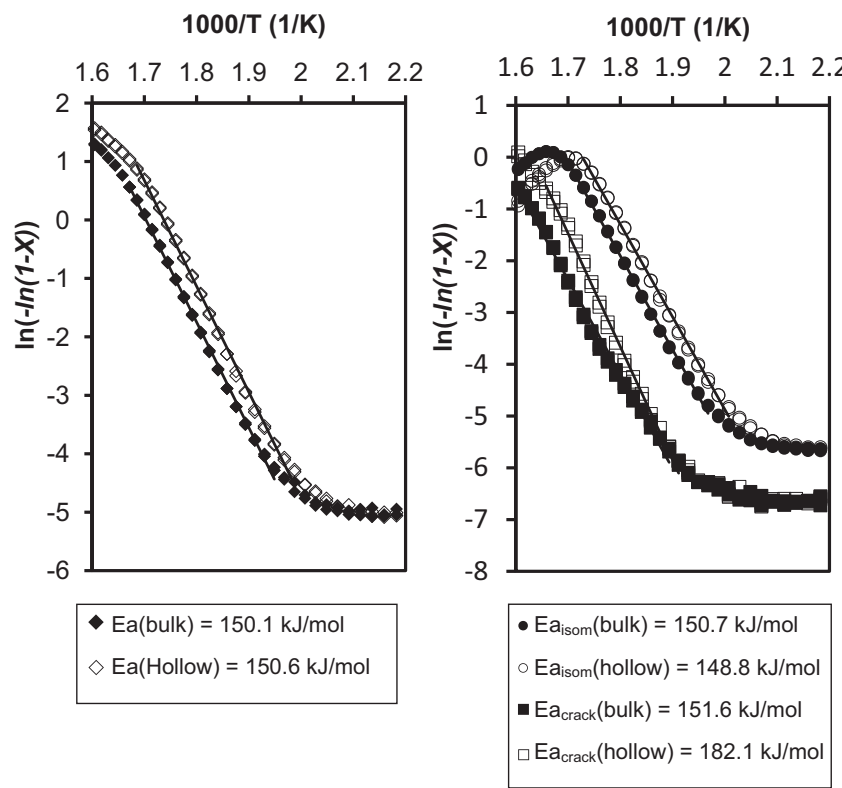

Fig. 7. Global apparent activation energies (left, diamond symbols) and activation energies in isomerization $\left(\mathrm{Ea}_{\text {isom }}\right.$, disk symbols) and cracking ( $\mathrm{Ea}_{\text {crack }}$, square symbols) reactions for hollow (open symbols) and bulk (filled symbols) zeolites.

similar to those obtained for isomerization $\left(\mathrm{Ea}_{\mathrm{isom}}=\right.$ $150.7 \pm 1 \mathrm{~kJ} / \mathrm{mol})$ and cracking $\left(\right.$ Ea $_{\text {crack }}=151.6 \pm$ $1.5 \mathrm{~kJ} / \mathrm{mol}$ ) reactions. In contrast, these values significantly differ on hollow crystals for which the activation energy of cracking $\left(\mathrm{Ea}_{\text {crack }}=182.1 \pm 1.5 \mathrm{~kJ} / \mathrm{mol}\right)$ exceeds that of isomerization $\left(\mathrm{Ea}_{\text {isom }}=148.8 \pm 1 \mathrm{~kJ} / \mathrm{mol}\right)$ by more than $30 \mathrm{~kJ} / \mathrm{mol}$. This unexpected difference is not yet fully understood but it could explain, at least partially, the higher activity and cracking affinity of hollow crystals in the hydroisomerization of $n$-hexadecane.

\section{Conclusion}

A post-synthesis strategy has been developed to obtain hollow Y zeolite crystals from standard bulk analogs. It is based on a three-step process including dealumination, acid washing and selective desilication in the presence of protective $\mathrm{Al}$ species. Each of the three steps necessitates to optimize experimental conditions as well as the composition of the zeolite framework and the distribution of $\mathrm{Al}$ species all over the crystals. As a consequence, final crystals are highly siliceous and characterized by relatively high framework $\mathrm{Si} / \mathrm{Al}$ ratios. Hollow crystals are highly crystalline, stable at elevated temperature and they possess $0.10-0.15 \mathrm{~nm}$ thick purely microporous walls. Different techniques tend to show that their surface is enriched with aluminum and that the corresponding $\mathrm{Al}$ species are not necessarily at framework positions but rather in extraframework amorphous sodium aluminosilicate phases. Due to the low $\mathrm{Al}$ content, crystals possess a weak acidity, characterized by a high proportion of Lewis acid sites, resulting from the presence of non-framework $\mathrm{Al}$ species. After mixing with a Pt-supported alumina binder, they could nonetheless be used as bifunctional catalysts in the hydroisomerization of $n$-hexadecane. For a given amount of zeolite, hollow crystals show a higher Brønsted sites average turnover frequency than bulk analogs, which was attributed for the most part to their specific morphology. Catalytic data show that bulk crystals do not work at their full potential and that approx. $50 \%$ of their internal volume is not used in the reaction. Hollowing out crystals removes their useless part and significantly improves the effectiveness of the zeolite in the reaction, as already reported for the hydrogenation of cyclohexene over Pt nanoparticles supported on hollow faujasites [53].

\section{References}

1 Tanabe K. (1999) Industrial application of solid acid-base catalysts, Appl. Catal. A: General 181, 399-434.

2 Vermeiren W., Gilson J.-P. (2009) Impact of zeolites on the petroleum and petrochemical industry, Top. Catal. 52, 1131-1161.

3 Agudelo J.L., Hensen E.J.M., Giraldo S.A., Hoyos L.J. (2015) Influence of steam-calcination and acid leaching treatment on the VGO hydrocracking performance of faujasite zeolite, Fuel Process. Technol. 133, 89-96.

4 Deshmukh A.R.A.S., Gumaste V.K., Bhawal B.M. (2000) Alkylation of benzene with long chain (C8-C18) linear primary alcohols over zeolite-Y, Catal. Lett. 64, 247-250.

5 Breck D.W. (1964) Crystalline Zeolite Y. US patent 3,130,007A, assigned to Union Carbide Corp.

6 Olson D. (1969) The crystal structure of the zeolite hydrogen faujasite, J. Catal. 13, 221-231.

7 Tosheva L., Valtchev V.P. (2005) Nanozeolites: Synthesis, crystallization mechanism, and applications, Chem. Mater. 17, 2494-2513.

8 Choi M., Na K., Kim J., Sakamoto Y., Terasaki O., Ryoo R. (2009) Stable single-unit-cell nanosheets of zeolite MFI as active and long-lived catalysts, Nature 461, 246-249. 
9 Borel M., Dodin M., Daou T.J., Bats N., Harbuzaru B., Patarin J. (2017) SDA-free hydrothermal synthesis of highsilica ultra-nanosized zeolite Y, Cryst. Growth Des. 17, 1173-1179.

10 Zhang X., Liu D., Xu D., Asahina S., Cychosz K.A., Agrawal K.V., Al Wahedi Y., Bhan A., Al Hashimi S., Terasaki O., Thommes M., Tsapatsis M. (2012) Synthesis of self-pillared zeolite nanosheets by repetitive branching, Science $\mathbf{3 3 6}$, 1684-1687.

11 Holmberg B.A., Wang H., Yan Y. (2004) High silica zeolite Y nanocrystals by dealumination and direct synthesis, Microporous Mesoporous Mater. 74, 189-198.

12 van Donk S., Janssen A.H., Bitter J.H., de Jong K.P. (2003) Generation, characterization, and impact of mesopores in zeolite catalysts, Catal. Rev. 45, 297-319.

13 Schuster C., Hölderich W.F. (2000) Modification of faujasites to generate novel hosts for "ship-in-a-bottle" complexes, Catal. Today 60, 193-207.

14 Qin Z., Shen B., Yu Z., Deng F., Zhao L., Zhou S., Yuan D., Gao X., Wang B., Zhao H., Liu H. (2013) A defect-based strategy for the preparation of mesoporous zeolite Y for highperformance catalytic cracking, J. Catal. 298, 102-111.

15 Pérez-Ramírez J., Christensen C.H., Egeblad K., Christensen C.H., Groen J.C. (2008) Hierarchical zeolites: Enhanced utilisation of microporous crystals in catalysis by advances in materials design, Chem. Soc. Rev. 37, 2530.

16 Parlett C.M.A., Wilson K., Lee A.F. (2013) Hierarchical porous materials: Catalytic applications, Chem. Soc. Rev. 42, 3876-3893.

17 Serrano D.P., Escola J.M., Pizarro P. (2013) Synthesis strategies in the search for hierarchical zeolites, Chem. Soc. Rev. 42, 4004-4035.

18 Verboekend D., Vilé G., Pérez-Ramírez J. (2012) Hierarchical $\mathrm{Y}$ and USY zeolites designed by post-synthetic strategies, Adv. Funct. Mater. 22, 916-928.

19 Holm M.S., Taarning E., Egeblad K., Christensen C.H. (2011) Catalysis with hierarchical zeolites, Catal. Today 168, $3-16$.

20 García-Martínez J., Johnson M., Valla J., Li K., Ying J.Y. (2012) Mesostructured zeolite Y - high hydrothermal stability and superior FCC catalytic performance, Catal. Sci. Technol. 2, 987-994.

21 Zhou L., Shi M., Cai Q., Wu L., Hu X., Yang X., Chen C., $\mathrm{Xu}$ J. (2013) Hydrolysis of hemicellulose catalyzed by hierarchical H-USY zeolites - The role of acidity and pore structure, Microporous Mesoporous Mater. 169, 54-59.

22 Wang Y., Lin M., Tuel A. (2007) Hollow TS-1 crystals formed via a dissolution-recrystallization process, Microporous Mesoporous Mater. 102, 80-85.

23 Wang Y., Tuel A. (2008) Nanoporous zeolite single crystals: ZSM-5 nanoboxes with uniform intracrystalline hollow structures, Microporous Mesoporous Mater. 113, 286-295.

24 Pagis C., Morgado Prates A.R., Farrusseng D., Bats N., Tuel A. (2016) Hollow zeolite structures: An overview of synthesis methods, Chem. Mater. 28, 5205-5223.

25 Morgado Prates A.R., Pagis C., Meunier F.C., Burel L., Epicier T., Roiban L., Koneti S., Bats N., Farrusseng D., Tuel A. (2018) Hollow beta zeolite single crystals for the design of selective catalysts, Cryst. Growth Des. 18, 592-596.

26 Pagis C., Morgado Prates A.R., Bats N., Tuel A., Farrusseng D. (2018) High-silica hollow Y zeolite by selective desilication of dealuminated $\mathrm{NaY}$ crystals in the presence of protective $\mathrm{Al}$ species, CrystEngComm 20, 1564-1572.
27 Li S., Aquino C., Gueudré L., Tuel A., Schuurman Y., Farrusseng D. (2014) Diffusion-driven selectivity in oxidation of $\mathrm{CO}$ in the presence of propylene using zeolite nano shell as membrane, ACS Catal. 4, 4299-4303.

28 Li S., Boucheron T., Tuel A., Farrusseng D., Meunier F. (2014) Size-selective hydrogenation at the subnanometer scale over platinum nanoparticles encapsulated in silicalite-1 single crystal hollow shells, Chem. Commun. 50, 1824-1826.

29 Li S., Tuel A., Rousset J.-L., Morfin F., Aouine M., Burel L., Meunier F., Farrusseng D. (2016) Hollow zeolite singlecrystals encapsulated alloy nanoparticles with controlled size and composition, ChemNanoMat 2, 534-539.

30 Farrusseng D., Tuel A. (2016) Perspectives on zeoliteencapsulated metal nanoparticles and their applications in catalysis, New J. Chem. 40, 3933-3949.

31 Ginter D.M., Bell A.T., Radke C.J. (1992) The effects of gel aging on the synthesis of $\mathrm{NaY}$ zeolite from colloidal silica, Zeolites 12, 742-749.

32 Klinowski J. (1984) Nuclear magnetic resonance studies of zeolites, Progr. Nucl. Magn. Reson. Spectrosc. 16, 237-309.

33 Groen J.C., Moulijn J.A., Pérez-Ramírez J. (2007) Alkaline posttreatment of MFI zeolites. From accelerated screening to scale-up, Ind. Eng. Chem. Res. 46, 4193-4201.

34 Beyer H.K. (2002) Dealumination techniques for zeolites, Post-Synthesis Modification I, Springer, Berlin, Heidelberg, pp. 203-255.

35 Fichtner-Schmittler H., Lohse U., Engelhardt G., Patzelová V. (1984) Unit cell constants of zeolites stabilized by dealumination determination of $\mathrm{Al}$ content from lattice parameters, Cryst. Res. Technol. 19, K1-K3.

36 Kubelková L., Dudíková L., Bastl Z., Borbély G., Beyer H.K. (1987) Aluminium distribution in the bulk and on the surface of $\mathrm{Y}$ zeolites dealuminated with $\mathrm{SiCl}_{4}$ vapour. Influence of conditions of dealumination, J. Chem. Soc. Faraday Trans. 1 83, 511-516.

37 Yuan D., Kang C., Wang W., Li H., Zhu X., Wang Y., Gao X., Wang B., Zhao H., Liu C., Shen B. (2016) Creation of mesostructured hollow Y zeolite by selective demetallation of an artificial heterogeneous Al distributed zeolite crystal, Catal. Sci. Technol. 6, 8364-8374.

38 Lutz W., Löffler E., Zibrowius B. (1993) Increased hydrothermal stability of highly dealuminated Y zeolites by alumination, Zeolites 13, 685-686.

39 Verboekend D., Nuttens N., Locus R., Van Aelst J., Verolme P., Groen J.C., Pérez-Ramírez J., Sels B.F. (2016) Synthesis, characterisation, and catalytic evaluation of hierarchical faujasite zeolites: milestones, challenges, and future directions, Chem. Soc. Rev. 45, 3331-3352.

40 Deshpande R.R., Eckert H. (2009) Sol-gel preparation of mesoporous sodium aluminosilicate glasses: mechanistic and structural investigations by solid state nuclear magnetic resonance, J. Mater. Chem. 19, 3419.

41 Emeis C.A. (1993) Determination of integrated molar extinction coefficients for infrared absorption bands of pyridine adsorbed on solid acid catalysts, J. Catal. 141, 347-354.

42 Boréave A., Auroux A., Guimon C. (1997) Nature and strength of acid sites in HY zeolites: a multitechnical approach, Microporous Mater. 11, 275-291.

43 Taylor R.J., Petty R.H. (1994) Selective hydroisomerization of long chain normal paraffins, Appl. Catal. A: General 119, 121-138. 
44 Deldari H. (2005) Suitable catalysts for hydroisomerization of long-chain normal paraffins, Appl. Catal. A: General 293, $1-10$.

45 Weitkamp J. (2012) Catalytic hydrocracking-mechanisms and versatility of the process, ChemCatChem 4, 292-306.

46 Alvarez F., Ribeiro F.R., Perot G., Thomazeau C., Guisnet M. (1996) Hydroisomerization and Hydrocracking of Alkanes, J. Catal. 162, 179-189.

47 Guisnet M. (2013) "Ideal" bifunctional catalysis over Pt-acid zeolites, Catal. Today 218-219, 123-134.

48 Batalha N., Pinard L., Bouchy C., Guillon E., Guisnet M. (2013) n-Hexadecane hydroisomerization over Pt-HBEA catalysts. Quantification and effect of the intimacy between metal and protonic sites, J. Catal. 307, 122-131.

49 Zecevic J., Vanbutsele G., de Jong K.P., Martens J.A. (2015) Nanoscale intimacy in bifunctional catalysts for selective conversion of hydrocarbons, Nature 528, 245-248.

50 Soualah A., Lemberton J.L., Pinard L., Chater M., Magnoux P., Moljord K. (2008) Hydroisomerization of long-chain n-alkanes on bifunctional $\mathrm{Pt} /$ zeolite catalysts: Effect of the zeolite structure on the product selectivity and on the reaction mechanism, Appl. Catal. A: General 336, $23-28$.

51 Mendes P.S.F., Silva J.M., Ribeiro M.F., Duchêne P., Daudin A., Bouchy C. (2017) Quantification of metal-acid balance in hydroisomerization catalysts: A step further toward catalyst design, AIChE J. 63, 2864-2875.

52 Verheyen E., Jo C., Kurttepeli M., Vanbutsele G., Gobechiya E., Korányi T.I., Bals S., Van Tendeloo G., Ryoo R., Kirschhock C.E.A., Martens J.A. (2013) Molecular shape-selectivity of MFI zeolite nanosheets in n-decane isomerization and hydrocracking, J. Catal. 300, 70-80.

53 Pagis C., Meunier F.C., Schuurman Y., Tuel A., Dodin M., Franco-Martinez R., Farrusseng D. (2018) Demonstration of improved effectiveness factor of catalysts based on hollow single crystal zeolites, ChemCatChem 10, 4525-4529. 